\title{
Studi Pengelolaan Uji Kompetensi Keahlian Berlisensi Lembaga Sertifikasi Profesi Pada Jurusan Teknik Mesin di Smkn 1 Blitar
}

\author{
Andika Setiawan ${ }^{1}$, Widiyanti $^{2}$, Sunomo $^{3}$ \\ ${ }^{1,2,3}$ Program Studi S1 Pendidikan Teknik Mesin Jurusan Teknik Mesin \\ ${ }^{1,2,3}$ Fakultas Teknik Universitas Negeri Malang \\ 1,2,3 Jalan Semarang No. 5, Malang 65145 \\ Email: andikademangan13@gmail.com
}

\begin{abstract}
Abstrak: Uji kompetensi keahlian berlisesnsi LSP di SMKN 1 Blitar bertujuan untuk menyertifikasi peserta didiknya terhadap kompetensi yang dimiliki selema menempuh pembelajaran di sekolah. Sertifikat LSP diberikan oleh siswa yang berkompeten dan diterbitkan langsung oleh Badan Nasional Sertifikasi Profesi (BNSP). Dengan adanya sertifikat ini siswa akan mendapat pengakuan terhadap kompetensi yang dimilikinya. Pengelolaan uji kompetensi LSP ini terdiri dari beberapa tahap yaitu, persiapan, pelaksanaan, evaluasi dan penerbitan sertifikat. Selain seagai pengakuan sertifikat ini diharapakan bisa menjadi pertimbangan dalam penyerapan tenaga kerja di dunia usaha maupun dunia industri.
\end{abstract}

Kata Kunci: Pengelolaan, Uji Kompetensi Keahlian, LSP

\begin{abstract}
ICP proficiency skill competency test at SVHS 1 Blitar aims to certify learners to the competence of having a dilemma of learning in school. The LSP certificate is awarded by students who are competent and issued directly by the National Agency for Profession Certification. With this certificate students will get recognition of the competence they have. Management of ICP competency test consists of several stages namely, preparation, implementation, evaluation and issuance of certificates. In addition to recognition of this certificate is expected to be a consideration in the absorption of labor in the world of business and industry.
\end{abstract}

Keywords: Management, Skill Competency Test, LSP

Uji Kompetensi Keahlian (UKK) adalah bagian dari intervensi Pemerintah dalam menjamin mutu pendidikan pada satuan pendidikan Sekolah Menengah Kejuruan. Pe-laksanaan UKK bertujuan untuk me-ngukur pencapaian kompetensi siswa pada level tertentu sesuai Kompetensi Keahlian yang ditempuh selama masa pembelajaran di SMK. UKK terdiri dari Ujian Praktik Kejuruan yang umumnya diselenggarakan sebelum pelaksanaan Ujian Nasional dan Ujian Teori Kejuruan yang merupakan bagian dari rangkaian pelaksanaan Ujian Nasional.

Pelaksanaan uji kompetensi di SMK sendiri setidaknya memiliki dua tujuan. Uji kompetensi sebagai penentu seseorang dalam pemenuhan kebutuhan kualifikasi dan lulus uji kompetensi, serta sebagai informasi dan peng-konfirmasi seseorang dimana di-nyatakan telah mampu mengerjakan pekerjaan yang sesuai dengan standar yang telah ditetapkan sebelumnya. Pengadaan Uji Kompetensi Keahlian ini diharapkan mampu meningkatkan kualitas lulusan SMK sehingga mampu memasuki dunia kerja yang se-sungguhnya. Penerapan uji kom-petensi keahlian ini berlaku untuk sekolah menengah kejuruan (SMK).

Berdasarkan Peraturan Pe-merintah Republik Indonesia Nomor 31 Tahun 2006 Tentang Sistem Pelatihan Kerja Nasional yang mengacu pada peningkatan kompetensi dan pro-duktivitas kerja pada sebuah lembaga pelatihan kerja. SMKN 1 Blitar telah membentuk Lembaga Sertifikasi Profesi Pihak Pertama (LSP-P1), maka dari itu pelaksanaan uji kompetensi keahliannya juga diselenggarakan oleh LSP-P1, terutama pada jurusan teknik pe-mesinan. Selain itu, pembentukan LSP-P1 di SMKN 1 Blitar dikarenakan sekolah tersebut telah memenuhi persyaratan dari pihak BNSP. LSP Pihak Pertama (LSP-P1) dibentuk oleh SMK yang memiliki akreditasi A dan mendapat rekomendasi dan atau penunjukan dari Direktoran Pembinaan SMK atau Dinas Pendidikan Provinsi dan memiliki skema sertifikasi sesuai dengan kurikulum pendidikan dari SMK yang bersangkutan.

Pelaksanaan uji kompetensi yang diselenggarakan oleh LSP ber-tujuan agar lulusan SMK mendapat sertifikat, dimana sertifikat tersebut sebagai bukti pengakuan terhadap bidang kompetensi yang dimilikinya. Proses uji kompetensi dilakukan oleh seorang asesor kompetensi yang di-laksanakan pada tempat uji kompetensi (TUK). Pengelolaan uji kompetensi LSP ini memiliki beberapa tahapan yaitu, (1) persiapan sekolah, (2) pelaksanaan uji kompetensi, (3) pe-nilaian dan penerbitan sertifikat. Dengan adanya penelitian ini akan didapatkan deskripsi mengenai tahapan pengelolaan uji kompetensi keahlian berlisensi LSP di SMKN 1 Blitar. Deskripsi ini nantinya dapat digunakan sebagai rujukan bagi sekolah lain dalam menyelenggarakan uji kompetensi keahlian berlisensi LSP. Pemerintah juga dapat menjadikan penelitian ini sebagai bahan sosialisasi di dunia usaha maupun industri terkait sertifikat LSP sebagai pertimbangan rekrutmen tenaga kerja. 


\section{METODE PENELITIAN}

Penelitian dilaksanakan meng-gunakan pendekatan kualitatif dengan rancangan studi kasus. Penelitian ini dilaksanakan di SMKN 1 Blitar pada jurusan teknik mesin. Subjek penelitian dipilih dengan berdasar pada kom-petensi subyek yang harus sesuai dengan fokus penelitian (Slamet, 2017) yaitu (1) Ketua LSP SMKN 1 Blitar, (2) Ketua Jurusan Teknik Mesin, (3) Kepala Bidang Mutu, (4) Kepala Bidang Setifikasi, (5) Asesor ujian LSP, dan (6) Siswa peserta Ujian LSP. Teknik pengambilan data dilakukan dengan wawancara, doku-mentasi dan observasi. Selanjutnya tek-nik analisis data yang digunakan adalah triangulasi teknik pengumpulan data dan sumber pengumpulan data (Sugi-yono, 2016). Analisis data setelah pengumpulan data dilakukan dengan pengkodean (Mol-eong, 2016).

\section{HASIL PENELITIAN}

Hasil penelitian ditemukan bahwa Persiapan pelaksanaan uji kometensi keahlian berlisensi LSP tidak hanya pada persoalan ad-ministrasi saja, tetapi sekolah juga mempersiapkan siswa untuk me-lakukan latihan dalam program Bimbingan Teknis (BIMTEK) se-belum menghadapi uji kompetensi supaya didapatkan hasil yang mak-simal.

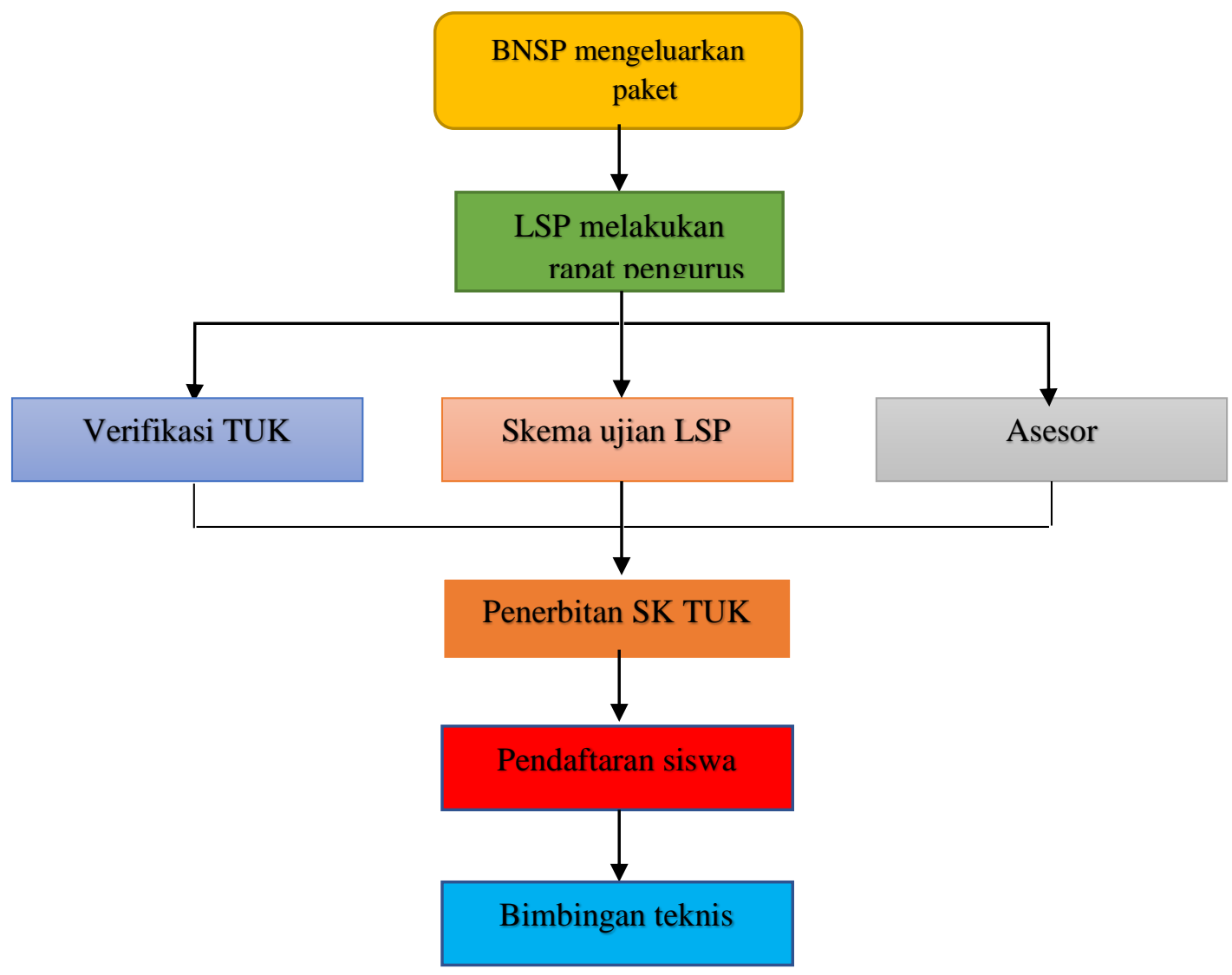

Gambar 1. Bagan Persiapan Pelaksanaan Ujian LSP

Teknis pelaksanaan ujian LSP pada jurusan teknik mesin di SMKN 1 Blitar sebagai berikut. (1) sehari sebelumnya siswa mengisi perangkat asesmen, (2) siswa menyerahkan perangkat asesmen kepada asesor, (3) siswa melakukan persiapan/brifing, (4) siswa melaksanakan ujian tulis (5) siswa melaksanakan tes wawancara, (6) siswa melaksanakan ujian praktek, (7) asesor melakukan penilaian, (8) asesor menyampaikan hasil penilaian. 


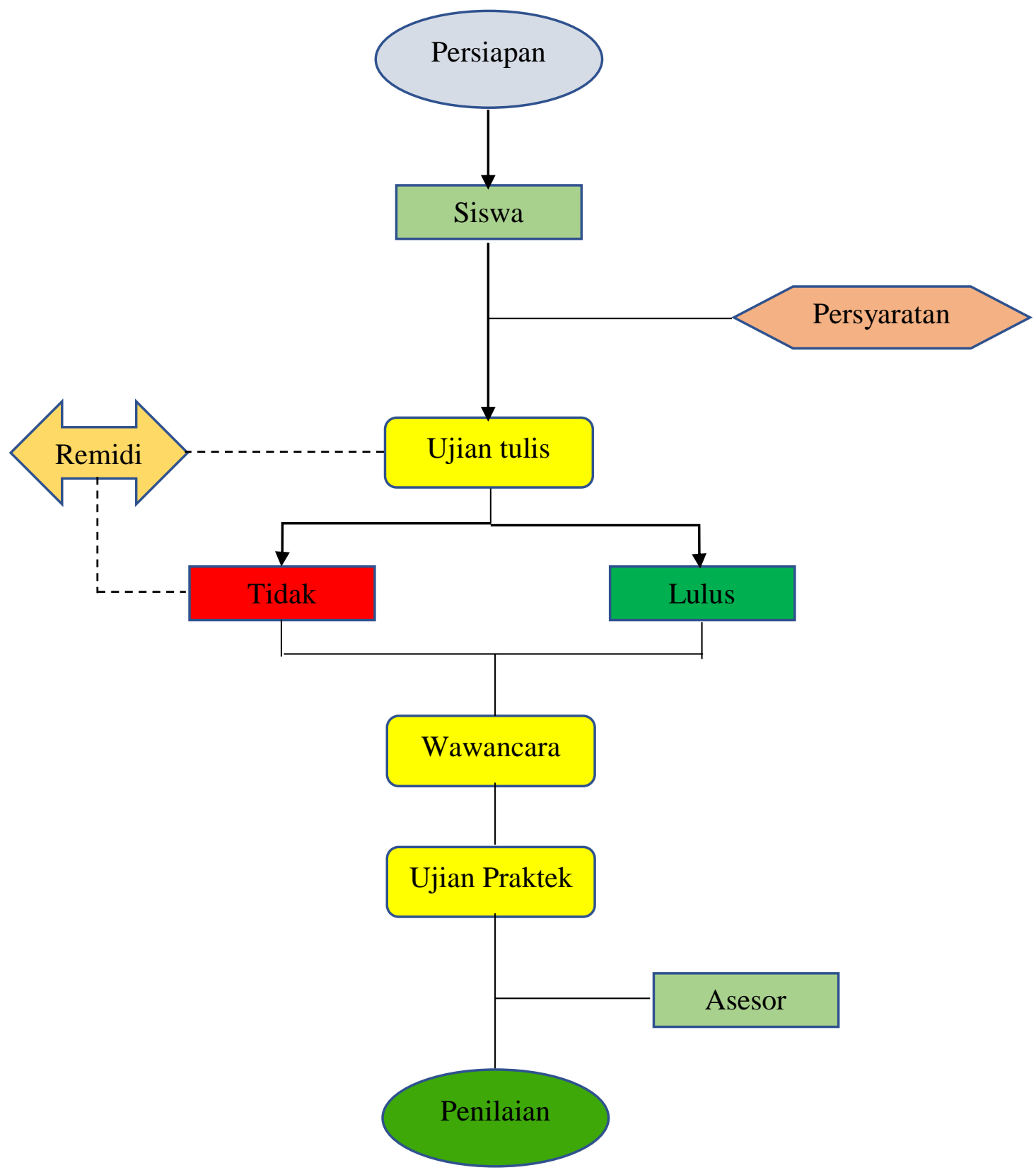

Gambar 2. Bagan Teknis Pelaksanaan Uji Kompetensi Keahlian LSP

Uji kompetensi keahlian ber-lisensi LSP tidak hanya ujian praktek saja, tetapi juga ada ujian teori yang terdiri dari ujian tulis dan tes wawancara. Penilaian ujian LSP dilakukan berdasarkan kriteria lulus yang tercantum dalam Materi Uji Kompetensi (MUK) yang disusun dalam Perangkat Asesmen. Proses penilaian ujian tulis dilakukan lang-sung oleh asesor dengan mencocokan pada pedoman penilaian di MUK. Penerbitan sertifikat LSP di-awali dari rapat pleno semua panitian ujian LSP. Setelah itu dibuatkan permohonan penerbitan sertifikat dan langsung dikirim ke BNSP. Dari pihak BNSP akan menghitung jumlah sertifikat yang diminta lalu dikirim kembali ke LSP dalam bentuk sertifikat kosong yang berlogo garuda. Dari pihak LSP akan men-cetak sesuai data dan akan diserahkan kepada siswa yang di-nyatakan kom-peten. 


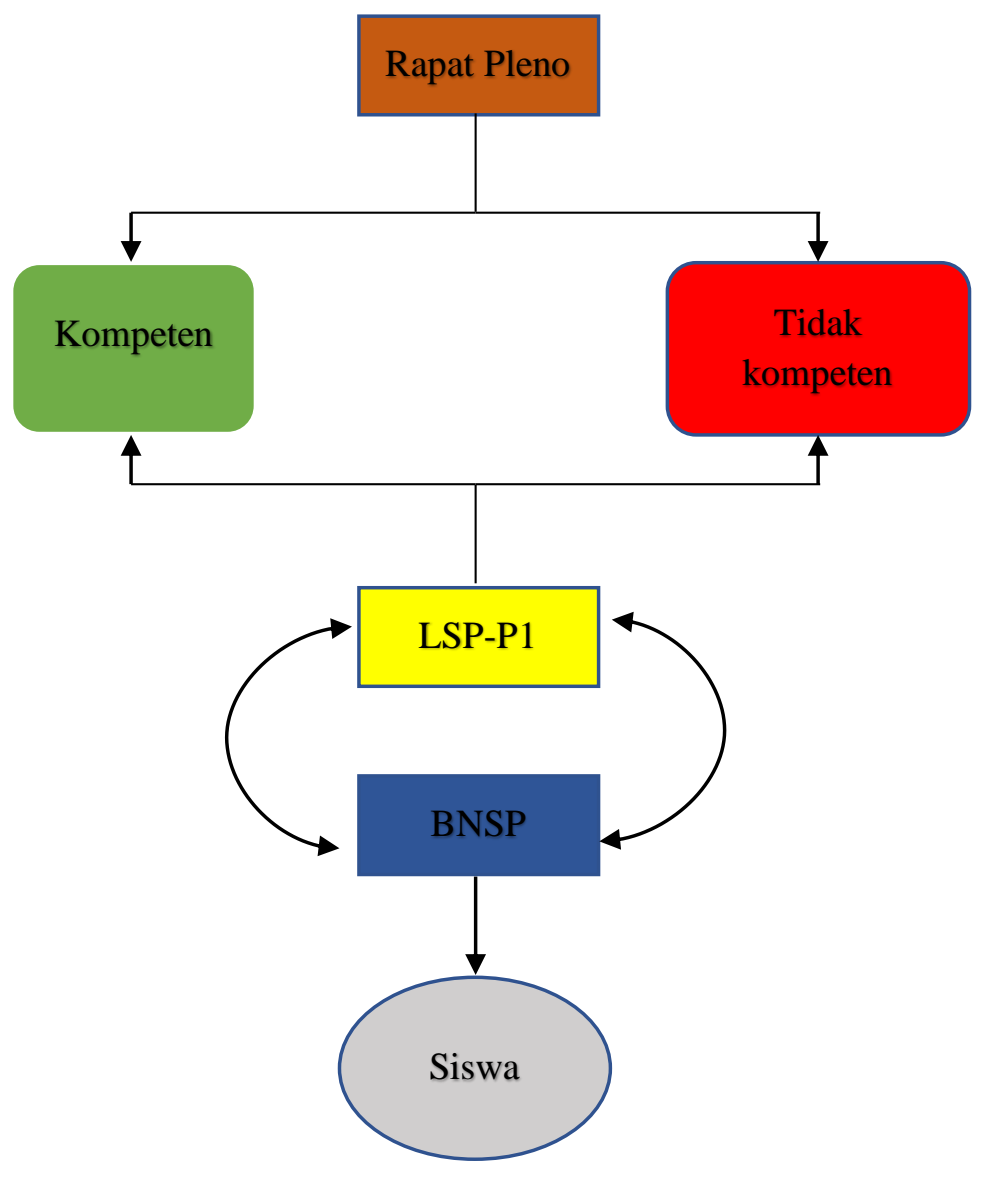

Gambar 3. Proses Penerbitan Sertifikat LSP

\section{PEMBAHASAN}

\section{Persiapan Sekolah dalam Menyusun Perencanaan Uji Kompetensi Keahlian (UKK) berlisensi LSP di SMKN 1 Blitar}

Persiapan merupakan langkah penting sebelum pelaksanaan Uji Kompetensi Keahlian Berlisensi LSP. Dengan persiapan yang baik, maka akan menjamin susksesnya pelaksanaan Uji Kompetensi Keahlian Berlisensi LSP di SMKN 1 Blitar. Persiapan pelaksanaan uji kompetensi keahlian berlisensi LSP sepenuhnya dilakukan oleh pihak LSP-P1 SMKN 1 Blitar. Dimulai dari rapat koordinasi seluruh pengurus ujian LSP. Selanjutnya Ketua LSP menentukan asesor dangan berkoordinasi dengan pihak LSP dilembaga lain tentang asesor yang akan didatangkan atau di-silangkan. Selanjutnya sekretaris me-lakukan penggandakan dokumen bagi peserta ujian dan Materi Uji Kompetensi (MUK) pada setiap skema yang diujikan. Setelah itu, dilakukan verifikasi tempat uji kompetensi (TUK) yang dilakukan oleh Ketua Bidang Mutu. Setelah tempat uji kompetensi dinyatakan layak sesuai skema maka verifikator merekomendasikan untuk diterbitkan Surat Keterangan Tempat Uji Kompetensi (TUK). Selain per-siapan adminitrasi, pihak sekolah juga menyiapkan siswa peserta ujian LSP agar dapat melaksanakan ujian dengan baik dan benar sehingga dapat mendapat hasil yang maksimal. Sekolah telah mengadakan latihan sebelum pe-laksanaan ujian yang dinamakan Bimbingan Teknis (BIM-TEK).

Persiapan lain yang juga membarengi pesiapan administratif di atas, terdapat pula persiapan yang dilakukan oleh siswa. Sekolah mengusahakan agar siswanya dapat melaksanakan uji kompetensi dengan mendapatkan hasil yang maksimal. Oleh sebab itu, maka sebelum siswa mengikuti ujian praktek pemesinan, terlebih dahulu dilakukan Bimbingan Teknis (BIMTEK) selama12 minggu. Dalam waktu tersebut siswa diberikan benda kerja dan jobsheet yang hampir sama dengan soal yang akan nantinya akan diujikan saat pelaksanaan uji kompetensi keahlian LSP.

Dalam persiapan pelaksanaan uji kompetensi, terdapat beberapa hal yang harus dipertimbangkan supaya pelaksanaan uji kompetensi keahlian dapat berjalan dengan baik. Hal yang harus dipertimbangkan dalam per-siapan pelaksanaan uji kompetensi kahlian LSP di SMKN 1 Blitar adalah (1) Tempat pelaksanaan, (2)Tempat Uji Kompetensi (TUK), apakah tempat pelaksaan uji kompetensi dan sarana prasaran harus memadai untuk di-laksanaan uji kompetensi, (3) pemilihan asesor, asesor yang akan menguji harus memenuhi syarat yang ditetapkan, (4) skema yang akan diujikan, dan (5) siswa yang akan mengikuti uji 
kompetensi. Hal ini didukung oleh hasil penelitian yang dilakukan oleh Putri (2017:105) tentang hal yang perlu dipertimbangankan untuk kesiapan pe-laksanaan uji kompetensi keahlian SMK yakni (1) Tempat pelaksanaan, (2)sarana prasarana, (3) pemilihan asesor, (4) waktu pelaksanaan, dan (5) siswa yang akan mengikuti uji kompetensi.

Untuk mengikuti uji kom-petensi keahlian berlisensi LSP siswa harus memenuhi beberapa per-syaratan sebagai berikut. (1) Siswa harus sudah kelas 12 yang sudah mengikuti UAS semester 5 (2) Nilai pelajaran produktif/praktek diatas KKM (3) Siswa harus sudah me-laksanakan dan lulus PRAKERIN (4) Siswa harus sudah mengikuti Bimbingan Teknis (BIMTEK). Selain persyaratan diatas terdapat juga persyaratan administrasi yang harus dipenuhi siswa sebagai berikut. (1) Mengumpukan fotocopy rapot semester 1-5 (2) Mengumpulkan fotocopy kartu pelajar (3) Me-ngumpulkan fotocopy ijazah SMP-/MTS (4) Mengumpulkan foto-copy sertifikat PRAKERIN (5) Meng-umpulkan fotocopy sertifikat BIM-TEK (6) Mengumpulkan pas foto 3x4 3 lembar (7) Mendaftar di LSP-P1 SMKN 1 Blitar (8) Membayar biaya ujian (bagi yang tidak di-rekomendasikan). Hal tersebut sesuai persyaratan permohonan sertifikasi yang terdapat pada Skema Sertifikasi Lembaga Sertifikasi Profesi Pihak Pertama (LSP-P1) SMKN 1 Blitar.

Pemilihan asesor/penguji oleh SMKN 1 Blitar telah sesuai dengan ketentuan yang ditetapkan pada Pedoman UKK 2018. Adapun hasil yang telah didapatkan adalah sebagai berikut. (1) Memiliki pengalaman menjadi guru selama 2-3 tahun,

(2) Berkompeten dibidang yang sesuai dengan skema ujian LSP, (3) Harus memiliki sertifikat sebagai asesor yang dikeluarkan oleh BNSP, (4) Memiliki pengalaman menjadi asesor pada ujian LSP, (5) Bersedia menjadi asesor pada ujian LSP di instansi lain.

Soal-soal uji kompetensi me-rupakan unsur yang penting dalam pelaksanaan uji kompetensi keahlian. Pembuatan soal ujian LSP dibuat berdasakan pada skema yang ditentukan oleh jurusan. Pada tahun ini skema yang ditentukan oleh jurusan teknik mesin adalah Pengoperasian Mesin Bubut Dasar. Soal-soal ujian tersebut dimuat dalam perangkat asesmen Materi Uji Kompetensi (MUK) dimana dalam skema terdapat beberapa kompetensi yang harus dimiliki oleh peserta ujian LSP. Hal tersebut selaras dengan apa yang tercantum di dalam Pedoman UKK 2017 (2017:6) mengenai ketentuan mengenai soal uji kompetensi, yakni SMK atau lembaga sertifikasi yang mendapatkan lisensi dari BNSP sebagai Lembaga Sertifikasi Profesi diperkenankan untuk me-nyelenggarakan ujian praktik sesuai dengan ruang lingkup skema sertifikasi yang telah di-tetapkan.

\section{Pelaksanaan Uji Kompetensi Keahlian Berlisensi LSP Pada Jurusan Teknik Mesin Di SMKN 1 Blitar}

Pelaksanaan Uji Kompetensi Keahlian oleh LSP diselenggarakan sebelum ujian nasional dimulai. Pada jurusan teknik mesin SMKN 1 Blitar pelaksanaannya pada bulan Januari dan diikuti oleh 20 siswa yang telah direkomendasikan oleh jurusan dan sudah mendaftar ke LSP-P1 SMKN 1 Blitar. Dalam pelaksanaan Ujian LSP pada jurusan teknik mesin di-se-lenggarakan dalam berbagai tahapan yang harus diselesaikan oleh peserta ujian. Ujian pertama bagi peserta adalah ujian teori selanjutnya ujian wawancara dan yang terakhir ujian praktik. Hal ini sesuai dengan proses uji kompetensi yang dijelaskan pada Skema Sertifikasi LSP-P1 SMKN 1 Blitar yang men-jelaskan (1) Uji kompetensi yang dirancang oleh LSP P-1 SMKN 1 Blitar untuk menilai kompetensi terdiri dari beberapa metode, yaitu secara tidak langsung yang berupa tes tertulis dan lisan, secara langsung yang berupa tes praktik, pengamatan atau cara lain yang handal dan obyektif, serta berdasarkan dan konsisten dengan skema sertifikasi. (2) LSP P-1 SMKN 1 Blitar mempunyai prosedur untuk menjamin konsistensi administrasi uji kompetensi. (3) LSP P-1 SMKN 1 Blitar menetapkan, men-dokumentasikan dan memantau kriteria untuk kondisi administrasi uji kom-petensi.(4) LSP P-1 SMKN 1 Blitar akan menjamin bahwa pralatan teknis yang digunakan dalam proses pengujian (apabila ada) telah diverifikasi atau dikalibrasi secara tepat.

Pelaksanaan uji kompetensi keahlian berlisensi LSP pada jurusan teknik mesin Di SMKN 1 Blitar pada tahun ajaran 2018/2019 diikuti oleh 20 siswa. Ujian LSP ini berlangsung hanya dalam 1 hari yaitu pada tanggal 20 Januari 2018. Ujian LSP terdiri dari ujian tulis, tes wawancara, dan ujian praktek. Alokasi waktu yang diberikan siswa dalam menyelesaikan ujian yaitu, (1) ujian tulis selama 15 menit, (2) tes wawancara selama 5-10 menit, (3) ujian praktek selama 100 menit. Dalam ujian praktek siswa akan diberi waktu tambahan 10 menit jika belum me-nyelesaikan jobnya.

\section{Penilaian Dan Sertifikasi Uji Kompetensi Keahlian Berlisensi LSP Pada Jurusan Teknik Mesin Di SMKN 1 Blitar}

Uji kompetensi keahlian berlisensi LSP tidak hanya ujian praktek saja, tetapi juga ada ujian teori yang terdiri dari ujian tulis dan tes wawancara. Penilaian ujian LSP dilakukan berdasarkan kriteria lulus yang tercantum dalam Materi Uji Kompetensi (MUK) yang disusun dalam Perangkat Asesmen. Proses penilaian ujian tulis dilakukan langsung oleh asesor dengan men-cocokan pada pedoman penilaian di MUK.

Syarat-syarat lulus uji kom-petensi keahlian didapatkan dari kesesuaian hasil ujian dengan pedoman yang ada di Materi Uji Kompetensi (MUK). Hasil ujian dinyatakan berkompeten jika nilai yang didapat siswa memenuhi nilai batas bawah yaitu 7,0. Bagi siswa yang berkompeten akan di-rekomendasikan untuk mendapat sertifikat yang diterbitkan langsung oleh Badan Nasional Sertifikasi Profesi (BNSP). Pernyataan tersebut diperkuat dengan kriteria kelulusan yang terdapat pada Pedoman Pelaksanaan UKK 2018 (2018:18) yang menjelaskan pada UKK yang dilaksanakan SMK bekerja sama dengan LSP, guru produktif dan/atau asesor melakukan konversi dari sertifikat di LSP kedalam skala 70-100.

Penerbitan sertifikat LSP diawali dari rapat pleno semua panitian ujian LSP. Setelah itu dibuatkan permohonan penerbitan sertifikat dan langsung dikirim ke BNSP. Dari pihak BNSP akan menghitung jumlah sertifikat yang diminta lalu dikirim kembali ke LSP dalam bentuk sertifikat kosong yang berlogo garuda. Dari pihak LSP akan mencetak sesuai data dan akan di-serahkan kepada siswa yang di-nyatakan kompeten. Dalam sertifikat tersebut berisi kompetensi-kom-petensi yang dimiliki siswa ber-dasarkan skema ujian. Fungsi dari sertifikat LSP dapat digunakan sebagai bahan pertimbangan bagi per-usahaan yang 
melakukan rekrutmen tenaga kerja. Tapi sertifikat LSP ini belum sepenuhnya berlaku disemua perusahaan. Penerbitan sertifikat LSP

\section{KESIMPULAN}

Dari penelitian mengenai pengelolaan uji kompetensi keahlian berlisesnsi LSP pada jurusan teknik mesin di SMKN 1 Blitar dapat disimpulkan sebagai berikut: (1) Pelaksanaan uji kompetensi keahlian berlisesnsi LSP merupakan sarana untuk mengukur kompetensi siswa yang mereka dapat selama mengikuti pembelajaran disekolah. Lisensi LSP disini bertujuan untuk memberi sebuah pengakuan terhadap kompetensi yang dimiliki siswa. Pengakuan tersebut dibuktikan dalam bentuk sertifikat yang diterbitkan langsung oleh Badan Nasional Sertifikasi Profesi (BNSP).

Pelaksanaan ujian LSP di SMKN 1 Blitar dimulai dengan banyak persiapan. Sebagai persiapan awal LSP mengadakan rapat koordinasi semua pengurus pada setiap event ujian. Dalam rapat tersebut membahas tentang skema ujian yang akan dipakai, selanjutnya LSP akan bekerja sama dengan LSP diinstansi lain untuk menentukan asesor, lalu bagian administrasi akan menyusun Materi Uji Kompetensi (MUK) dan mengeluarkan surat keterangan Tempat Uji Kompetensi (TUK). Setelah itu kepala TUK akan menyiapkan peserta ujian dimana selain persiapan administrasi kepala TUK juga mempersiapkan siswa dengan latihan uji kompetensi yang dinamakan Bimbingan Teknis (BIMTEK). Jika semua telah terpenuhi maka kepala TUK siap untuk mendaftarkan siswa, (2) Pelaksanaan UKK LSP di SMKN 1 Blitar sudah disesuaikan dengan skema sertifikasi yang dibuat oleh LSP. Selain itu SMKN 1 Blitar juga melaksanakan uji kompetensi keahlian sesuai dengan pedoman pelaksanaan UKK. Pelaksanaan UKK LSP di SMKN 1 Blitar hanya berlangsung 1 hari dikarenakan jumlah peserta hanya 20 siswa. Jadwal UKK LSP sudah direncanakan dengan cukup baik dengan menggelar UKK LSP sebelum Ujian Nasional. UKK LSP di SMKN 1 Blitar dilaksanakan pada tanggal 20 Januari 2018.

Uji kompetensi keahlian LSP di SMKN 1 Blitar melibatkan 2 asesor hasil pertukaran dari SMKN 3 Boyolangu. UKK LSP terdiri dari 3 rangkaian ujian yaitu ujian tulis, tes wawancara, dan ujian praktek. Ujian diawali siswa dengan brifing dan mengisi perangkt asesmen, lalu siswa melaksanakan ujian tulis dimana bagi siswa yang lulus bisa lanjut untuk tes wawancara sedangkan bagi yang tidak lulus akan diberi kesempatan remidi. Setelah itu siswa melaksanakan ujian praktek dengan job dan waktu yang telah ditetapkan yaitu 100 menit. Setelah waktu ujian selesai, asesor akan menilai langsung hasil ujian siswa. Hasil ujian siswa akan langsung diumumkan oleh asesor pada hari itu juga, hasil ujian siswa berupa pernyataan kompeten dan tidak kompeten. (3) Uji kompetensi keahlian berlisensi LSP tidak hanya ujian praktek saja, tetapi juga ada ujian teori yang terdiri dari ujian tulis dan tes wawancara. Penilaian ujian LSP dilakukan berdasarkan kriteria lulus yang tercantum dalam Materi Uji Kompetensi (MUK) yang disusun dalam Perangkat Asesmen. Syarat-syarat lulus uji kompetensi keahlian didapatkan dari kesesuaian hasil ujian dengan pedoman yang ada di Materi Uji Kompetensi (MUK). Hasil ujian di-nyatakan berkompeten jika nilai yang didapat siswa memenuhi nilai batas bawah yaitu 7,0. Penerbitan sertifikat LSP diawali dari rapat pleno semua panitian ujian LSP. Setelah itu di-buatkan permohonan penerbitan sertifikat dan langsung dikirim ke BNSP. Dari pihak BNSP akan men-ghitung jumlah sertifikat yang diminta lalu dikirim kembali ke LSP dalam bentuk sertifikat kosong yang berlogo garuda. Dari pihak LSP akan mencetak sesuai data dan akan diserahkan kepada siswa yang dinyatakan kompeten. Dalam sertifikat tersebut berisi kom-petensikompetensi yang dimiliki siswa berdasarkan skema ujian.

\section{SARAN}

Saran yang diberikan penulis yaitu (1) Kepada SMK yang sudah membentuk LSP-P1 disarankan untuk segera menyelenggarakan sertifikasi pada setiap jurusan agar kompetensi yang dimiliki siswa setelah lulus dapat diakui oleh pemerintah maupun industri dimasa depan. (2) Jurusan teknik mesin disarankan untuk terus menyediakan mesin-mesin yang berstandar dan berkualitas, sehingga LSP bisa me-laksanakan sertifikasi dengan banyak skema, dengan begitu semua siswa bisa mengikuti ujian LSP. (3) Pemerintah disarankan untuk lebih me-nambah jumlah bantuan paket pada setiap kesempatan me-nyelenggarakan ujian LSP. Bertambahnya jumlah bantuan paket akan menambah jumlah peserta ujian. Pemerintah juga disarankan untuk lebih mengenalkan sertifikat LSP ini kepada industri, sehingga industri juga bisa mengakui kompetensi yang dimiliki lulusan-lulusan dari SMK dan mem-pertimbangkannya saat pe-rekrutan tenaga kerja. (4) Kepada peneliti selanjutnya disarankan untuk membahas secara lebih mendalam tentang ujia kompetensi keahlian LSP-P1. Hal ini dimaksudkan karena ujian LSP ini pada kedepannya pasti akan di-selenggarakan oleh semua SMK dan bisa jadi syarat wajib bagi siswa untuk lulus sekolah. Peneliti selanjutnya juga disarankan untuk lebih mendalami tentang sertfikat LSP terkait pe-ngaruhnya terhadap DU/DI.

\section{DAFTAR RUJUKAN}

Budiyono, Aris. 2011.Uji Kom-petensi Keahlian Siswa Me-nengah Kejuruan. Jurnal Teknik Mesin. 40(01). 11-18.

Direktorat Pembinaan Sekolah Me-nengah Kejuruan. 2017. Pedoman Penyelenggaraan Uji Kompetensi Keahlian SMK Tahun Pelajaran 2016/2017. Jakarta: Ke-mendikbud

DPSMK. 2017. Panduan pe-laksanaan Uji Kompetensi ke-ahlian Tahun Ajaran 2017/2018. Jakarta: DPSMK.

Fathurrochim, Muhammad Rezky. 2017.Pelaksanaan Uji Kompetensi Di Tempat Uji Kompetensi Teknik Ken-daraan Ringan Lembaga Sertifikasi Profesi Sekolah Menengah Kejuruan Se-Kota Yogyakarta Skripsi, Yogyakarta: FT-UNY.

Hamdani, Wahyu. 2016.Model Pe-laksanaan Uji Kompetensi Kelas Kerjasama Program Keahlian Teknik Pemesinan, Malang: FT-UM. 
7. Andika Setiawan, Widiyanti, Sunomo Studi Pengelolaan Uji Kompetensi Keahlian Berlisensi...

Kurniawan, Ambar. 2016. Studi Evaluasi Pelaksanaan Uji Kompetensi Keahlian (UKK) Program Keahlian Teknik Pemesinan SMKN 2 Pasuruan Skripsi, Malang: FT-UM.

Moleong, L. J. 2016. Metodologi Penelitian Kualitatif. Ban-dung: Remaja Ro-sdakarya.

Noor .M. 2006. Modul Penelitian Kualitatif. Semarang: Untag-Fisip.

Peraturan Pemerintah Republik Indonesia Nomor 31 Tahun 2006 tentang Sistem Pelatihan Kerja Nasional

Prasetyo, Agus. 2015. Analisis Butir Soal Sertifikasi Kompetensi P1 Bidang Teknik Mesin Di LSP SMKN 1 Magelang Skripsi. Yogyakarta: FTUNY

Saputro, Desi Adi. 2016.Implementasi Pe-laksanaan Uji Kompetensi Keahlian Teknik Pemesinan Di SMK Negeri 1 Singosari Skripsi, Malang: FT-UM.

Sri Sundari. 2010. Pengelolaan Unit Produksi Berbasis Sosial (Studi Kasus Di SMK Negeri 4 Klaten). Tesis. Surakarta; Pascasarjana UMS.

Sugiyono. 2016. Memahami Pe-nelitian Kualitatif. Bandung: Alfabeta.

Sugiyono. 2016. Metode Penelitian Pendidikan. Bandung: Alfabeta.

Ulfatin, Nurul. 2015. Metode Penelitian Kualitatif di Bidang Pendidikan: Teori dan Aplikasinya. Malang: Media Nusa Creative

Undang-undang Nomor 20 Tahun 2003 Tentang Sistem Pen-didikan Nasional 